\title{
Lymphocytic profiling in thyroid cancer provides clues for failure of tumor immunity
}

\author{
Shahnawaz Imam ${ }^{1}$, Rodis Paparodis ${ }^{1,2}$, Deepak Sharma' and Juan Carlos Jaume ${ }^{1,2}$ \\ ${ }^{1}$ Endocrine Autoimmunity Unit, Division of Endocrinology, Diabetes and Metabolism, Department of Medicine, \\ School of Medicine and Public Health ${ }^{2}$ Veterans Affairs Medical Center, University of Wisconsin-Madison, \\ 1685 Highland Avenue, MFCB 4163, Madison, Wisconsin 53705, USA
}

Correspondence should be addressed to $\mathrm{J}$ C Jaume

Email

jcj@medicine.wisc.edu

\begin{abstract}
Thyroid cancers are usually surrounded by a significant number of immune-reactive cells. Tumor-associated lymphocytes as well as background lymphocytic thyroiditis are frequently mentioned in pathology reports of patients who have undergone surgery for thyroid cancer. The nature of this lymphocytic reaction is not well understood. The fact that cancer can survive in this adverse microenvironment is indicative of immune regulation. We characterized the lymphocytic infiltration that accompanies thyroid cancer and compared it with that present in thyroid autoimmunity. We found that double-negative (DN) T cells were significantly more abundant in thyroid cancer than in thyroid autoimmunity. Although $\mathrm{FOXP3}^{+}$regulatory T cells were also present, DN T cells were the dominant cell type, associated with thyroid cancer. Furthermore, upon stimulation, the DN T cells associated with cancer remained unchanged, while the few $(<5 \%)$ DN T cells associated with thyroid autoimmunity increased in numbers $(>20 \%)$. CD25 expression on DN T cells remained unchanged after stimulation, which indicates that the increase in the absolute number of DN T cells in thyroid autoimmunity was at the expense of inactivation of single-positive T cells. We concluded that in the setting of thyroid cancer, DN T cells appear to suppress tumor immunity. In contrast, in thyroid autoimmunity, DN T cells were barely present and only increased at the expense of inactivated, single-positive T cells upon induction. Together, these findings indicate that thyroid cancer-associated DN T cells might regulate proliferation and effector function of T cells and thereby contribute to tumor tolerance and active avoidance of tumor immunity.
\end{abstract}

\author{
Key Words \\ - Hashimoto thyroiditis \\ - thyroid cancer \\ - autoimmunity \\ tumor immunity
}

Endocrine-Related Cancer (2014) 21, 505-516

\section{Introduction}

Highly immunogenic tumors can spontaneously prime protective immunity, a phenomenon known as tumor immunity (Prehn \& Main 1957). However, poorly immunogenic tumors do not spontaneously induce tumor immunity nor do they prime functional T-cell responses (Turk et al. 2004). Unfortunately, such tumors represent a large proportion of cancers in humans, where antitumor
T-cell responses are often detected but do not control progression and/or may favor tumor growth (Romero et al. 1998, Valmori et al. 2002). In autoimmunity, on the other hand, immunity is induced to target self. Autoantigen-driven affinity maturation of $\mathrm{B}$ and $\mathrm{T}$ cells perfects the immune response to its most lethal form. Memory immune cells persist for life and facilitate chronic

Published by Bioscientifica Ltd. 
target destruction even under immunosuppressive conditions (Jaume 2011).

Thyroid cancer and thyroid autoimmunity seem to be situated at opposite extremes of the immune response spectrum. In thyroid cancer, the immune response seems tolerant, allowing for tumor growth. In thyroid autoimmunity, the immune response is destructive, leading to complete thyroid failure (Paparodis et al. 2014). Although known to immunologists for decades, it has re-emerged in recent years that more effective immunotherapy of cancer is associated with autoimmunity (Korman et al. 2005, Gogas et al. 2006). For example, the appearance of autoantibodies or clinical manifestations of autoimmunity during treatment with interferon $\alpha$ are associated with statistically significant improvements in relapse-free survival and overall survival of patients with melanoma (Gogas et al. 2006). In cancer development, progressive accumulation of genetic abnormalities renders cells malignant. The immune system seems to be allowing or even promoting cancer progression for some tumors (Balkwill et al. 2005). While immune regulation in cancer seems to support development and progression, immune dysregulation in autoimmunity leads to tissue destruction and elimination of the target.

Thyroid cancers are usually surrounded by a significant number of immune-reactive cells. Tumor-associated lymphocytes as well as lymphocytic infiltration organized in germinal centers (GC; chronic lymphocytic thyroiditis or Hashimoto thyroiditis) are frequently mentioned in pathology reports of patients who have undergone surgery for thyroid cancer (Chen et al. 2013). The nature of this lymphocytic reaction is not well understood. The fact that cancer can survive in this adverse microenvironment is indicative of immune regulation.

Suppression of immune responses by regulatory $\mathrm{T}$ cells (Tregs) is critical for the induction and maintenance of self-tolerance. Tregs have been shown to be involved in the downregulation of immune responses in autoimmunity, transplant rejection, and tumor immunity (Sakaguchi 2000, Baecher-Allan \& Anderson 2006). A variety of T-cell subsets possess immunoregulatory properties. The thymus-derived Treg (naturally occurring $\mathrm{CD} 4{ }^{+} \mathrm{CD} 25^{+} \mathrm{FOXP}^{+}$, Abbas et al. 2013) cells are the most extensively studied subset of Tregs and their role has been investigated in a wide range of animal models and in humans (Bennett et al. 2001, Kriegel et al. 2004). However, inducible Tregs such as T-regulatory type 1 (Tr1) cells, T-helper 3 (Th3) cells, $\mathrm{CD}^{+} \mathrm{CD}^{+} 8^{-}$ T cells, and $\mathrm{CD}^{+}{ }^{+} \mathrm{CD} 4^{-} \mathrm{CD} 8^{-}$double-negative (DN) T cells also exhibit the ability to inhibit immune responses (Groux et al. 1997, Wildin et al. 2001, Chang et al. 2002, Faria \& Weiner 2006, Zhang et al. 2006).
In this study, we characterized the lymphocytic infiltration that accompanies human papillary thyroid cancer (PTC; the most common form of thyroid cancer) and compared it with that present in human autoimmune thyroid disease (Hashimoto thyroiditis, the most common form of thyroid autoimmunity). Ex vivo aspirations of human thyroid glands affected by both diseases and controls were carried out. Lymphocytes were isolated and either analyzed immediately by flow cytometry or placed in culture and stimulated after $24 \mathrm{~h}$. Thyroid tissue specimens were also studied. We found that the lymphocytic microenvironment was critically different in both thyroid diseases and that immunity in thyroid cancer was under the control of an unexpected $\mathrm{T}$ cell player.

\section{Subjects and methods}

\section{Thyroid subjects}

The UW Thyroid Multidisciplinary Clinic is a large referral site for thyroid diseases. Patients referred for thyroid surgery include those with positive or suspicious cytology for malignancy on fine-needle aspiration (FNA) and those with goiter associated with compressive symptoms (such as dysphagia, shortness of breath or hoarseness). Hashimoto thyroiditis per se is not an indication for thyroid surgery; however, some patients develop compressive symptoms that require surgical intervention. For this study, we identified patients with cytology-proven thyroid cancer and Hashimoto thyroiditis. Patients undergoing thyroid surgery had their thyroids ex vivo aspirated in the operating room. A tissue sample from each patient was snap frozen in liquid nitrogen and stored for further analysis. Postoperative histology confirmed the presence of thyroid cancer and Hashimoto thyroiditis. For those patients with histology of Hashimoto's, we confirmed the diagnosis (hypothyroidism with abnormally high TSH and low free $\mathrm{T}_{4}$ levels) had been made before surgery. We only included Hashimoto's patients in whom hypothyroidism was not due to previous thyroid surgery or radioactive iodine treatment, but rather the pathological outcome of chronic thyroiditis causing thyroid failure. Established pathological characteristics were followed by our academic pathologists for the diagnosis of thyroid cancer and Hashimoto's. The diagnosis of Hashimoto thyroiditis relied on the presence of both thyroid follicles accompanied by lymphocytic infiltrates and the formation of GC (Fig. 1 top right as an example). Representative thyroid cancer sample coexisting with lymphocytic infiltration is shown in Fig. 1 top left. Patients diagnosed with either PTC $(n=11)$ or hypothyroid

Published by Bioscientifica Ltd. 

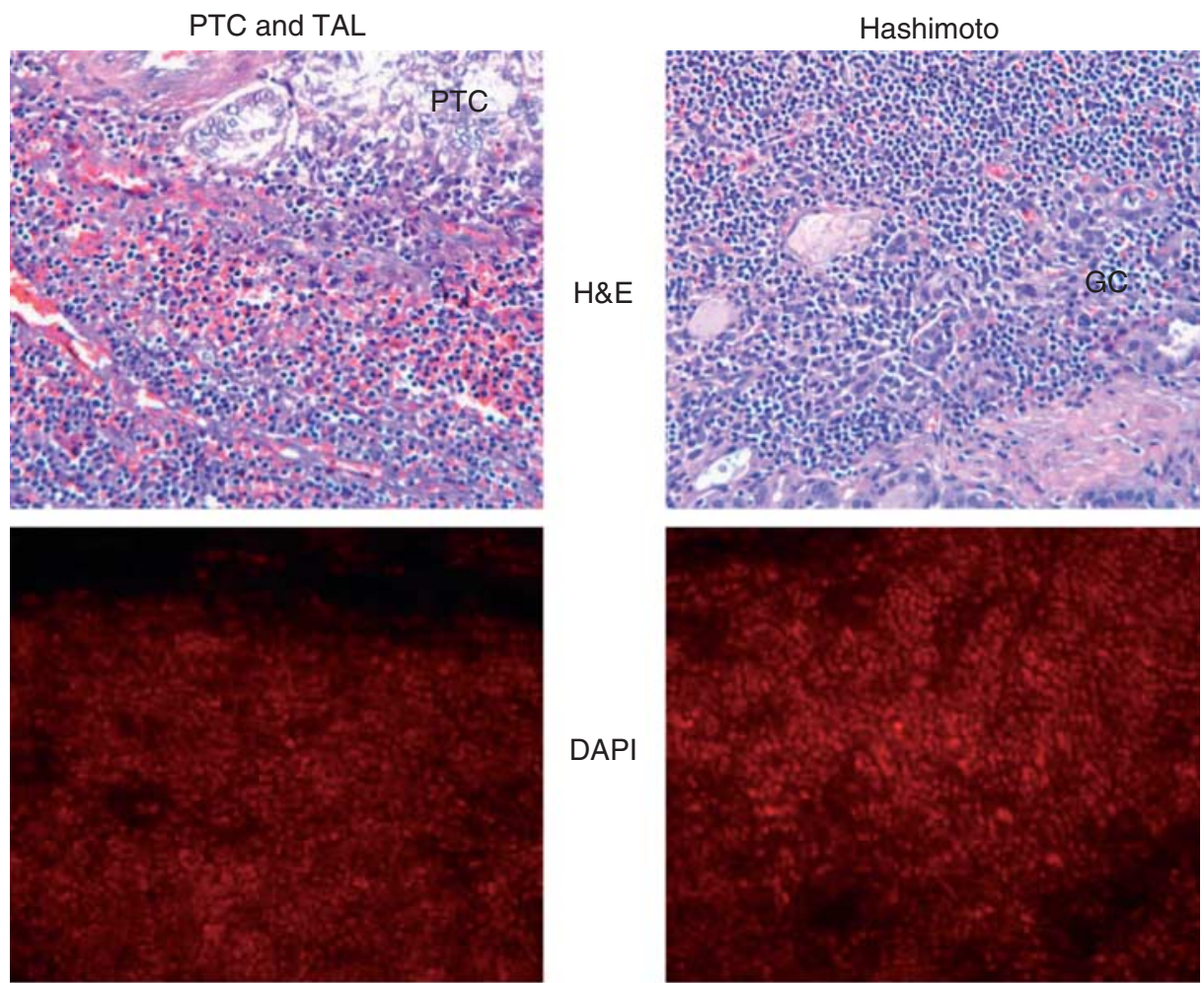

\section{DAPI}
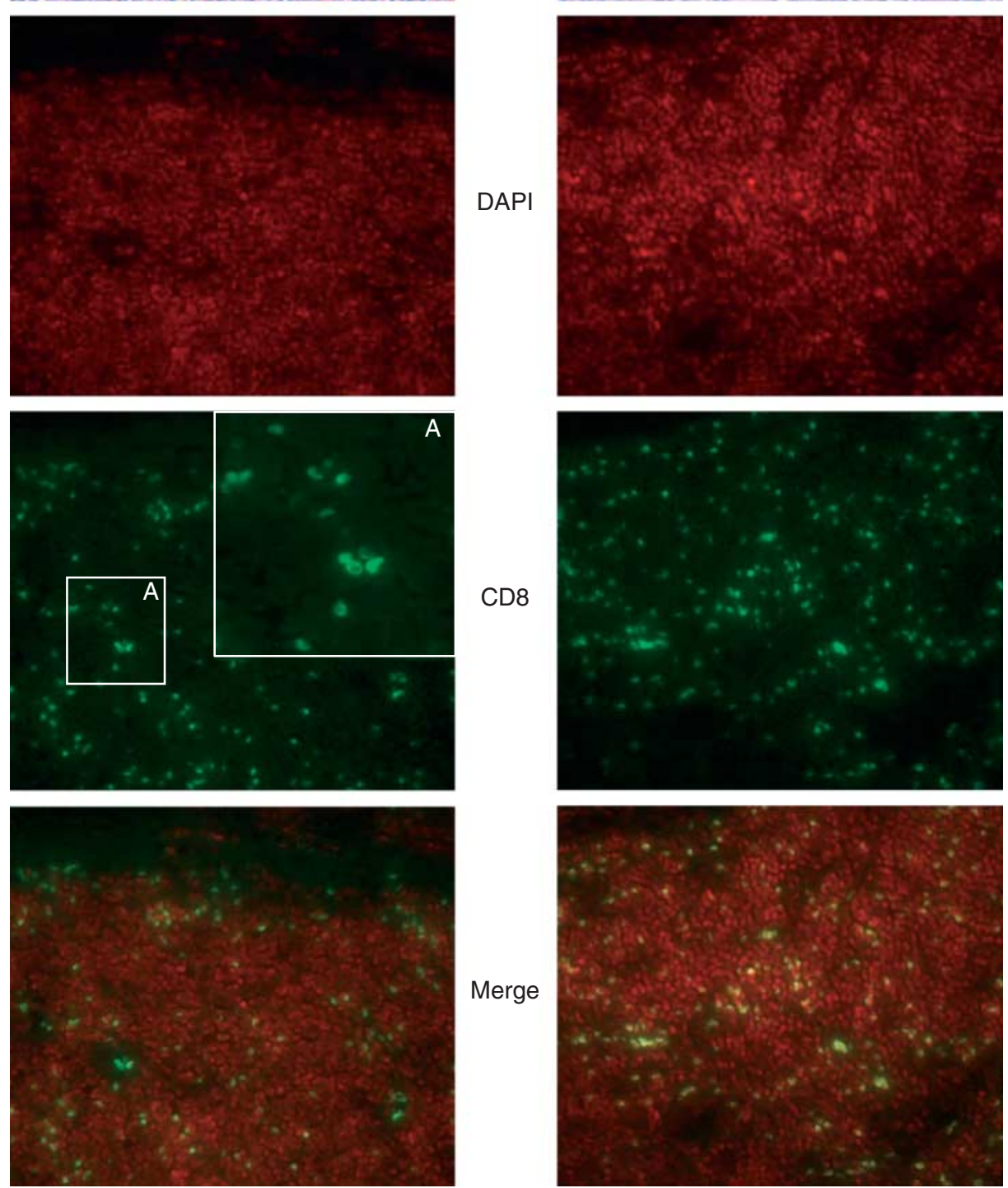

\section{Figure 1}

Surgical pathology. Hematoxylin/eosin and immunofluorescence staining. $40 \times$ magnification of representative surgical pathology specimens from patients with hypothyroid Hashimoto thyroiditis and papillary thyroid carcinoma (PTC) with tumor-associated lymphocytes (TAL) stained with hematoxylin/eosin (top). PTC, papillary thyroid carcinoma; GC, germinal

center-like structures. Images at the same magnification and representative specimens immunostained with DAPI (red for nuclei), anti-CD8 in green, and merged images of both are subsequently shown. Inset $(A)$ is a close-up of $\mathrm{CD}^{+}$stained cells.

Published by Bioscientifica Ltd 
Hashimoto thyroiditis (Hash, $n=7$ ) were studied. Controls (Ctr, $n=7$ ) included patients undergoing thyroid surgery for none of these conditions (i.e., symptomatic multinodular goiters). The collection of patient's tissue/data and subsequent analysis was approved by University of Wisconsin Human Subjects Institutional Review Board. Patients were invited to participate and sign consent pre-operatively to be part of this study.

\section{Tissue staining}

Frozen tissue sections were stained first with hematoxylin and eosin and used for basic histology and for correlation with specific immunohistochemistry/fluorescence studies. Anti-CD19 for identification of B-cell lineage, anti-CD3 for T-cell lineage, and anti-CD45 common leukocyte antigen (all 1:100 from BD Pharmingen, San Jose, CA, USA) were used as primary antibodies for immunohistochemistry. Secondary species-specific HRP-linked antibodies were developed using a commercial substrate (Vector, Burlingame, CA, USA). Histomorphometric microscopic studies were carried out in 15 or more randomly selected fields (as previously described in Mirocha et al. (2009)). Immunofluorescence was carried out on sections pre-treated for antigen retrieval with Retrivagen (BD Pharmingen) at $90^{\circ} \mathrm{C}$ for $10 \mathrm{~min}$. Endogenous peroxidase activity was quenched with $0.3 \%$ $\mathrm{H}_{2} \mathrm{O}_{2}$ for $10 \mathrm{~min}$ in PBS. For reduction of background staining, the sections were treated for $1 \mathrm{~h}$ with $5 \%$ normal serum from the same species as the labeling antibody used. The samples were then incubated with primary antibody in a humid chamber at $4{ }^{\circ} \mathrm{C}$ overnight. Primary antibodies used included anti-human CD4, and CD8 (all 1:100; BD Pharmingen). Secondary MAB, biotinylated and species-specific, were then stained with avidin-fluorescein (Vector). For counter staining, the cells were labeled with the nuclear stain DAPI (Molecular Probe, Eugene, OR, USA). For negative controls, samples were incubated with secondary antibody but not primary antibody. All immunofluorescence images were collected using a Bio-Rad Laser Scanning Confocal Microscope.

\section{Lymphocytes, isolation and staining}

The samples were ex vivo aspirated from the resected thyroid glands in the operation room and immediately mixed in RPMI media containing $10 \%$ FCS at $4{ }^{\circ} \mathrm{C}$. The red blood cells were lysed by a brief hypotonic shock. For all flow cytometry experiments, the cells were stained with fluorochrome-conjugated antibodies against human CD3,
CD4, CD8, CD14, CD19, CD25, CD45, CD56, and iNKT (anti-CD3-allophycocyanin/HIT3a, anti-CD4-APC-cy7/ RPA-T4, anti-CD8-PE-cy5/HIT8a, anti-CD14-PE/M5E2, anti-CD19-PE-cy5/HIB19, anti-CD25-PE/M-A251, antiCD45-FITC/HI30, anti-CD56-PE-cy7/B159, anti-iNKT FITC/6B11, TCR $\alpha \beta-F I T C / T 10 B 9.1 A-31$, and TCR $\gamma \delta-P E / B 1$; BD Biosciences (San Jose, CA, USA)) or isotype controls in serum-containing media. Freshly isolated single cells were incubated with antibodies for $20 \mathrm{~min}$ on ice for surface staining, washed, and fixed in 1\% paraformaldehyde. A subset of cells was permeabilized with cytofix/cytosperm fixation and permeabilization solution (BD Biosciences) and stained with fluorochrome-conjugated antibodies against human IL17, interferon $\gamma$ (IFN $\gamma$ ), and Foxp3 (anti-IL17-PE/N49-653, anti-IFN $\gamma$-PE/25723.11, antiFoxp3-Alexa Fluor 488/259D/C7; BD Biosciences). The cells were also stained with Hoechst $33342(10 \mu \mathrm{g} / \mathrm{ml}$ for $2 \mathrm{~h}$, Hoechst fluorescence, $350 \mathrm{~nm}$ excitation $/ 450 \mathrm{~nm}$ emission, linear scale) to gate live cells containing $2 n-4 n$ cellular DNA.

\section{Induction of lymphocytes}

A minimum of three million cells from each freshly isolated thyroid ex vivo aspirate were incubated in RPMI1640 with $10 \%$ FCS for $18 \mathrm{~h}$ at $37^{\circ} \mathrm{C}$ in a $5 \% \mathrm{CO}_{2}$ atmosphere. Then, cells were stimulated (induced) with phorbol 12-myristate 13-acetate (PMA, $50 \mathrm{ng} / \mathrm{ml}$ ), ionomycin $(1 \mu \mathrm{g} / \mathrm{ml})$, and Golgi plug brefeldin A $(1 \mu \mathrm{g} / \mathrm{ml})$, (SigmaAldrich) for $6 \mathrm{~h}$. The unstimulated cells served as controls.

\section{Flow cytometry data analysis}

All samples were prepared in triplicates and mean of the three samples was considered as individual data. In each replicate at least 10000 cells were acquired. The samples were acquired in a LSRII flow cytometer (BD Biosciences). Analysis of fluorescence-activated cell sorting (FACS) data was done with FlowJo v. 7.6.5 software (TreeStar Inc. Ashland, OR, USA). Analysis of the cell population was carried out based on four step criteria. The first step was the gating of lymphocytes on the basis of forward- and sidescatter characteristics. The second step was the removal of dead cells, debris and doublets on the basis of DNA integrity using Hoechst 33342 stain. The third step was the gating of T cells and non-T cells on the basis of CD3 expression. From CD3-gated cells, CD4 vs CD8 positive cells were plotted, which allowed the identification of discrete CD4, CD8 and DN T cell populations. Subsequent analyses were done on these individual cell populations.

Published by Bioscientifica Ltd. 


\section{Statistical analysis}

Since data were not normally distributed, data were transformed to natural logarithms or ranks. Individual end points were analyzed by group interactions. The SAS MIXED procedure (version 9.3, SAS Institute, Inc., Cary, NC, USA) was used for statistical analyses. Student's $t$-test or the Mann-Whitney $U$ test was used to identify the differences between the groups and controls. A probability of $P \leq 0.05$ indicated that a difference was significant, and a probability of $P>0.05$ to $P \leq 0.1$ indicated that a trend towards significance was approached. Data are presented as the mean S.E.M.

\section{Results}

We propose the hypothesis that intra-thyroidal lymphocytes accompanying thyroid cancer may be reactive to the presence of the tumor and different from lymphocytes found in autoimmune thyroid disease. To address our hypothesis, we designed a systematic characterization of the lymphocytic microenvironment of human postsurgical thyroid specimens.

\section{Subtle differences in thyroid autoimmunity and thyroid cancer lymphocytic milieu}

Patients with FNA cytology consistent with Hashimoto thyroiditis (hypothyroid by history), those with cytology positive for PTC, and those undergoing thyroid surgery for symptomatic multi-nodular goiters (controls) were identified. Patients' thyroid glands were ex vivo aspirated (for FACS) and small pieces of thyroid tissues snap frozen in liquid nitrogen (for staining) in the operating room. The frozen tissues were processed and stained first with hematoxylin/eosin (H\&E, Fig. 1 top as examples) and then with immunostains for characterization of the lymphocytic profile of the different thyroid conditions. $\mathrm{H} \& \mathrm{E}$ staining was not helpful in distinguishing the differences in lymphocytic infiltration (Fig. 1 top). Immunostaining, however, showed subtle differences among the groups. H\&E staining showed that patients with PTC had more dispersed lymphocytic infiltrates, while in the hypothyroid Hashimoto's patients the lymphocytic infiltration appeared to be more organized in structures resembling lymph-node GC. Nevertheless, GC were sometimes present in both groups. In specimens from hypothyroid Hashimoto's patients, many
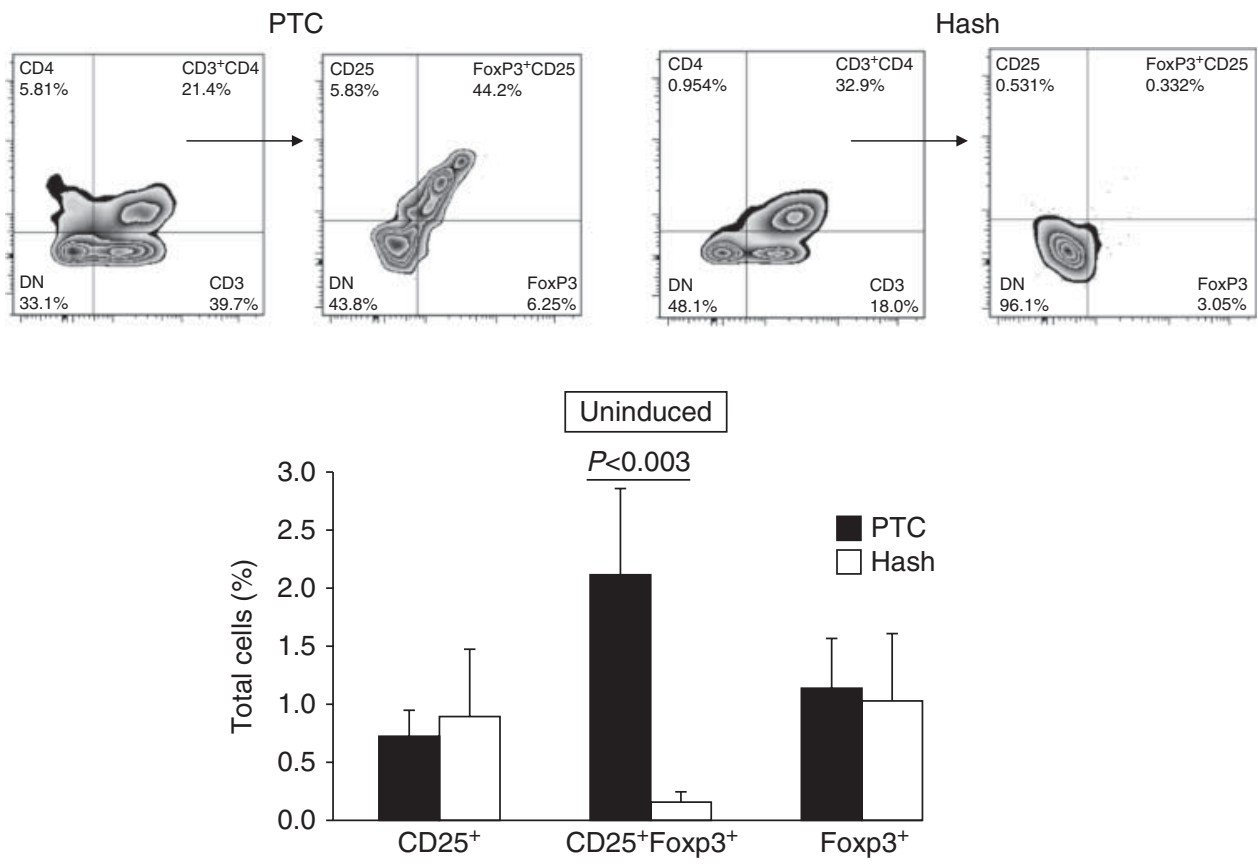

\section{Figure 2}

Flow cytometry of classic Tregs. (Top) Contours plots of $\mathrm{CD} 3^{+} \mathrm{CD} 4^{+}$ lymphocyte specimens from representative patients with papillary thyroid carcinoma (PTC) and hypothyroid Hashimoto thyroiditis (Hash). $\mathrm{CD}^{+}$and $\mathrm{CD}^{+}$gated T cells were sorted for CD25, Foxp3, and both (classic Tregs, $\mathrm{CD}^{+} \mathrm{CD}^{+} \mathrm{CD}^{2} 5^{+} \mathrm{FOXP3}^{+}$). (Bottom) Bar graph of statistical analysis of lymphocyte specimens from all patients of both groups. Percentages of $\mathrm{CD}^{+} \mathrm{CD}^{+}$gated T cells sorted for the same immune markers are shown. Black bars represent results for specimens from papillary thyroid cancer (PTC) patients. White bars represent results for specimens from hypothyroid Hashimotos' patients (Hash). http://erc.endocrinology-journals.org DOI: 10.1530/ERC-13-0436
(C) 2014 Society for Endocrinology Printed in Great Britain 
lymphocytes stained positive for CD8, while in specimens from patients with PTC, CD8-positive lymphocytes were less abundant (Fig. 1 DAPI for nuclei in red, CD8 in green, and merged images of both shown in bottom panels). Notably, many lymphocytes did not stain for either CD4 or CD8. Controls did not have measurable infiltrates and lymphocytes present were not different than what is expected in peripheral blood (not shown).

\section{FOXP3 $^{+}$Tregs were predominantly present in thyroid cancer but in low numbers}

The combined expression of CD4, CD25, and FOXP3 identifies FOXP3 ${ }^{+}$Tregs (Sakaguchi 2000). FOXP3 ${ }^{+}$Tregs were more numerous in PTC specimens, scarce in hypothyroid Hashimoto's ones and almost undetectable in controls (not shown). As expected from what we observed on histology, when ex vivo-extracted lymphocytes were analyzed by flow cytometry, in patients with PTC, the associated lymphocytic concentration of $\mathrm{FOXP3}^{+}$Tregs was higher than in patients with hypothyroid Hashimoto's (Fig. 2). However, although the difference was significant, as a percentage of the total lymphocytic population, the $\mathrm{FOXP}^{+}$Tregs represented $<2.5 \%$.

\section{$\mathrm{CD}^{+}{ }^{+} \mathrm{CD} 4^{-} \mathrm{CD}^{-}{ }^{-} \mathrm{T}$ cells stand out as the dominant $\mathrm{T}$ cell population in thyroid cancer}

FACS analysis revealed another group of $\mathrm{T}$ cells never described in the setting of thyroid cancer. $\mathrm{CD}^{+}{ }^{+} \mathrm{CD} 4^{-}$ $\mathrm{CD}^{-}$(double negative, DN) $\mathrm{T}$ cells were significantly more abundant in lymphocytic infiltrates accompanying thyroid cancer than in those present in hypothyroid Hashimoto's (Fig. 3) and only traceable in controls (not shown). Overall, DN T cells were the dominant T cell type associated with thyroid cancer. DN T cells were 20 times more abundant than classic Tregs in this setting. Reciprocally, $\mathrm{CD} 4^{+}$and $\mathrm{CD} 8^{+} \mathrm{T}$ cell counts were also significantly lower in thyroid cancer as seen in the histological analysis, while natural killer T (NKT) cells only displayed a trend towards lower levels (Fig. 3). Upon PMA/Ionomycin stimulation/induction (Fig. 4), the DN T cells associated with the thyroid cancer remained unchanged while the few $(<5 \%)$ DN $\mathrm{T}$ cells associated with hypothyroid Hashimoto's increased in absolute numbers $(>20 \%)$.

\section{IFN $\gamma$ and IL17 are augmented in thyroid cancer, mostly from DN T cells}

IFN $\gamma$ production from lymphocytes accompanying thyroid cancer was overall higher. A major contributor to

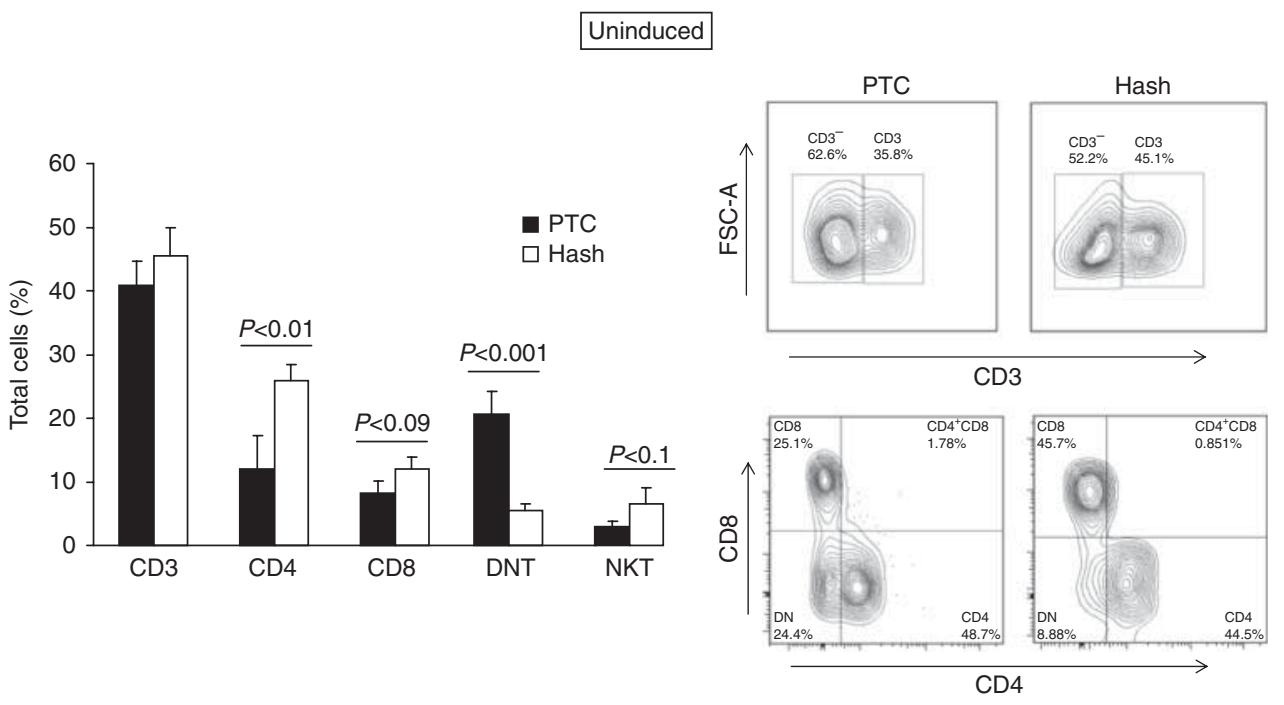

Figure 3

Flow cytometry of all uninduced T Cells. Contour plots of lymphocyte specimens from representative patients with papillary thyroid cancer (PTC) and hypothyroid Hashimoto thyroiditis (Hash) (right) and bar graphs of statistical analysis (left) of untreated (uninduced) lymphocyte specimens gated for CD3 and subsequently sorted for CD4, CD8, DNT, and NKT.
DNT stands for double negative and NKT stands for natural killer T cells. Black bars represent results for specimens from papillary thyroid cancer (PTC) patients. White bars represent results for specimens from hypothyroid Hashimotos' patients (Hash). http://erc.endocrinology-journals.org DOI: 10.1530/ERC-13-0436
(C) 2014 Society for Endocrinology Printed in Great Britain
Published by Bioscientifica Ltd. 

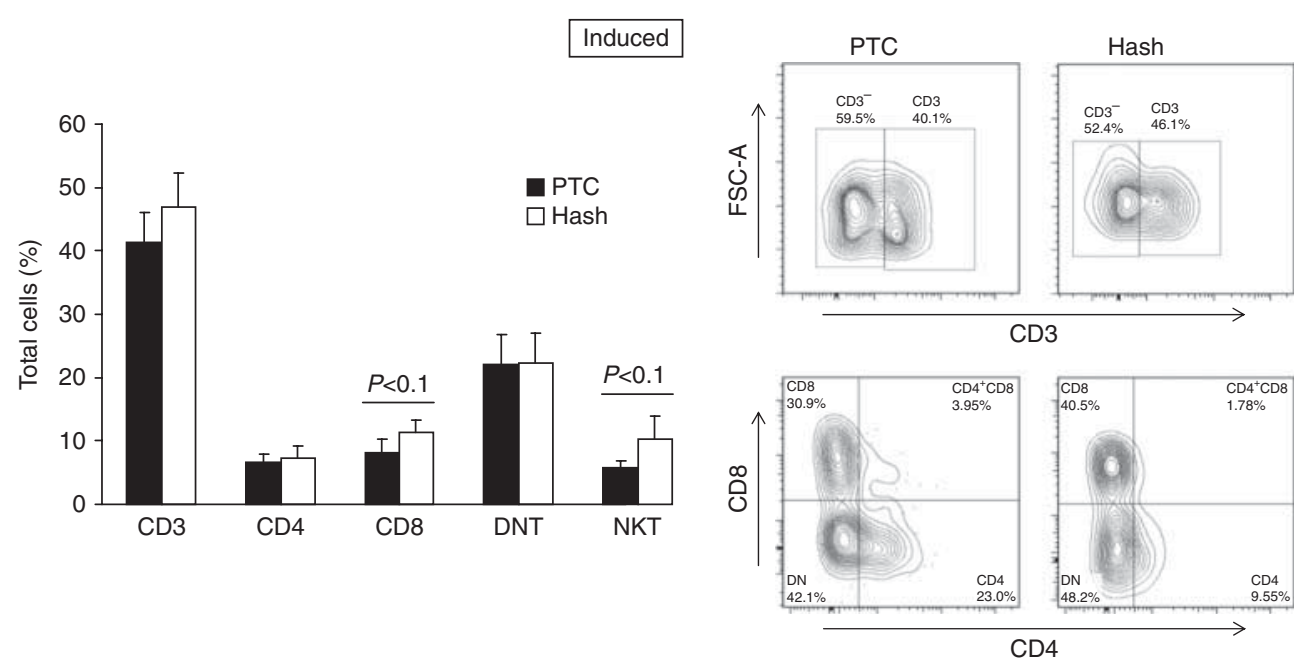

Figure 4

Flow cytometry of all induced T cells. Contour plots of lymphocyte specimens from representative patients with papillary thyroid cancer (PTC) and hypothyroid Hashimoto thyroiditis (Hash) (right) and bar graphs of statistical analysis (left) of PMA/ionomycin-treated (Induced) lymphocyte specimens gated for CD3 and subsequently sorted for CD4, CD8, DNT, and NKT.

this IFN $\gamma$ increase was the DN T cell population (over 40\%, Fig. 5). A similar observation was made for IL17 production although $\mathrm{CD} 4{ }^{+} \mathrm{T}$ cells were also contributors (Fig. 6). We interpreted the cytokine production as a regulatory phenomenon because it derived mostly from the DN $\mathrm{T}$ cells and reciprocally affected single-positive $\mathrm{T}$ cells (Figs 5 and 6). After PMA/ionomycin induction, there was a small reduction in IFN $\gamma$-producing $\mathrm{CD} 4{ }^{+} \mathrm{T}$ cells that was more pronounced in the Hashimoto's lymphocytes than in the thyroid-cancer-associated lymphocytes which rendered the difference between the two groups significant (Fig. 5). For IL17-producing $\mathrm{CD}^{+} \mathrm{T}$ cells that difference became almost significant as a consequence of both increased numbers in the thyroid cancer specimens and decreased numbers in Hashimoto's ones (Fig. 6). The opposite was observed for IL17-producing DN T cells which were decreased after induction in PTC and increased in Hash (Fig. 6).

\section{Activated DN T cells in thyroid cancer and inactived DN T cells in Hashimoto's}

The highest expression of CD25 ( $\alpha$ chain of the IL2 receptor and maker for activation) was found in DN T cells in the setting of thyroid cancer and remained almost unchanged (already maximized) after stimulation/induction (Fig. 7A). The expression of CD25 in DN T cells in the setting of hypothyroid Hashimoto's also remained unchanged, which
DNT stands for double negative and NKT stands for natural killer T cells. Black bars represent results for specimens from papillary thyroid cancer (PTC) patients. White bars represent results for specimens from hypothyroid Hashimotos' patients (Hash).

indicates that the increase in the absolute number of DN $\mathrm{T}$ cells (Fig. 4) was at the expense of inactivated singlepositive $\mathrm{T}$ cells (mostly $\mathrm{CD} 4{ }^{+} \mathrm{T}$ cells). PMA/ionomycin stimulation/induction is known to inhibit the expression of CD4 and CD8 in vitro (DiSanto et al. 1989, Jin et al. 2004). Therefore, the increase in DN T cells in Hashimoto's upon induction is probably the consequence of loss of CD4/CD8 expression (inactivated single-positive $\mathrm{T}$ cells).

\section{Macrophages, B cells, and all other monocytes were not particularly affected}

We also looked at the potential differences in CD19 (B cells), CD14 (macrophages), and CD45 (common leukocyte antigen) expression between the two groups of patients. Under both conditions, the number of macrophages was similar as was the number of B cells (albeit proportionally high as compared with expected peripheral counts and controls, Fig. 7B). Induction did not significantly affect CD19 and CD14 expression under either disease condition. CD45 expression accounted for most of the lymphocytes studied in both groups. Induction decreased overall expression more in thyroid-cancer-associated lymphocytes, but the differences were not significant (Fig. 7C).

\section{Discussion}

Glands from patients with Hashimoto thyroiditis had lymphocytic infiltrates functionally different from

Published by Bioscientifica Ltd. 

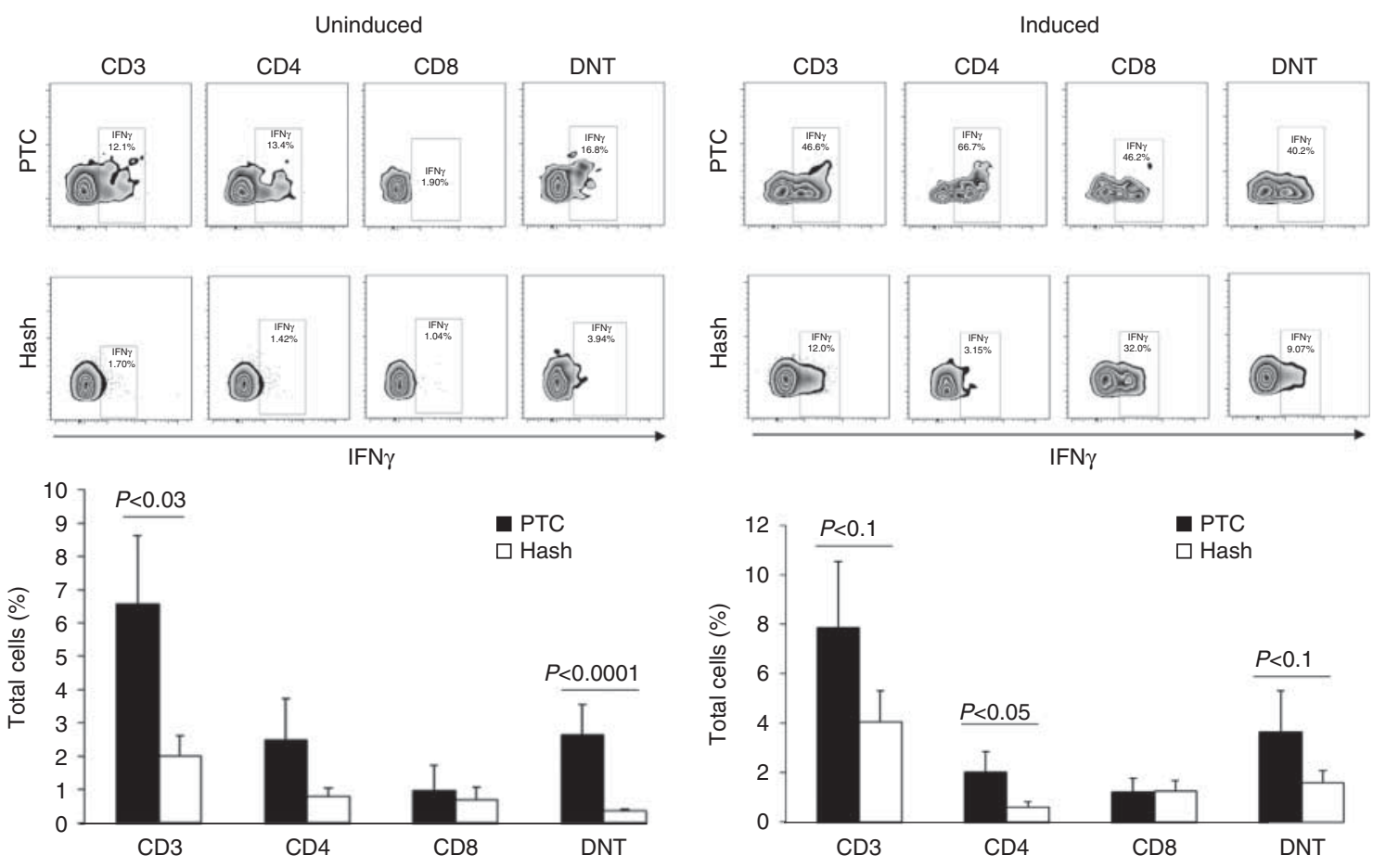

Figure 5

Interferon $\gamma$ production by T cell type. Interferon $\gamma$ (IFN $\gamma$ ) production from lymphocytes in patients with papillary thyroid cancer (PTC) and hypothyroid Hashimoto thyroiditis (Hash) is shown. (Left panels) Uninduced (untreated) lymphocyte FACS contour plots of representative patients (top) and bar graphs of statistical analysis of all T cells (bottom) by T cell type.

(Right panels) Induced (PMA/lonomycin treated) lymphocyte FACS contour

those accompanying thyroid cancers. Lymphocytes in Hashimoto's were mainly effector cells. Lymphocytes accompanying thyroid cancer appeared to be under $\mathrm{T}$ cell regulation. $\mathrm{CD}^{+}$and $\mathrm{CD} 8^{+} \mathrm{T}$ cells were significantly decreased, while $\mathrm{CD} 4^{-} \mathrm{CD}^{-} \mathrm{T}$ cells were significantly increased. This, to our knowledge, never previously described phenomenon may be explained by a few possibilities. One could be that the decreased count of $\mathrm{CD} 4^{+}$and $\mathrm{CD}^{+}{ }^{+}$cells in patients with thyroid cancer is the result of T cell 'exhaustion'. Indeed, T cell exhaustion has been described as a state of $\mathrm{T}$ cell dysfunction that arises during many chronic infections and cancer (Wherry 2011). T cells can recover from exhaustion by boosting immune responses (Wherry 2011). However, we did not observe recovery at least after short induction. Another possibility is that thyroid cancer negotiates its survival with the immune system by downregulating effector $\mathrm{T}$ cells while recruiting Tregs. The cancer 'immunoediting' hypothesis stresses the dual host-protective and tumorpromoting actions of immunity in the development of tumors (Schreiber et al. 2011). Specifically, it proposes

plots of representative patients (top) and bar graphs of statistical analysis of all T cells (bottom) by T cell type. Black bars represent results for specimens from papillary thyroid cancer (PTC) patients. White bars represent results for specimens from hypothyroid Hashimotos' patients (Hash).

three phases of immune modulation of cancer development (elimination, equilibrium, and escape) which help to explain our observations and give us a mechanistic framework for our hypothesis. Lymphocytes in Hashimoto's are clearly capable of elimination of the target. As with anti-CTLA-4 immunotherapy, exacerbation of rampant autoimmunity may help to eliminate cancer (Mellman et al. 2011). Lymphocytes accompanying thyroid cancer on the opposite extreme appear to be in equilibrium with cancer. The immune response in thyroid cancer seems tolerant to the presence of the tumor as if it was regulated. We found higher numbers of FOXP3 ${ }^{+}$Tregs in the thyroid cancer immune microenvironment compared with Hashimoto's. However, Hashimoto's specimens were from patients with long-standing disease that required surgery either because of compressive symptoms (fibrosis) or pain (painful thyroiditis). Surprisingly, we found that the regulatory immune component in thyroid cancer was represented by an unexpected player.

In both mice and humans, about $1-5 \%$ of all peripheral $\mathrm{T}$ cells are of $\mathrm{DN}$ phenotype. These $\mathrm{T}$ cells do

Published by Bioscientifica Ltd. 

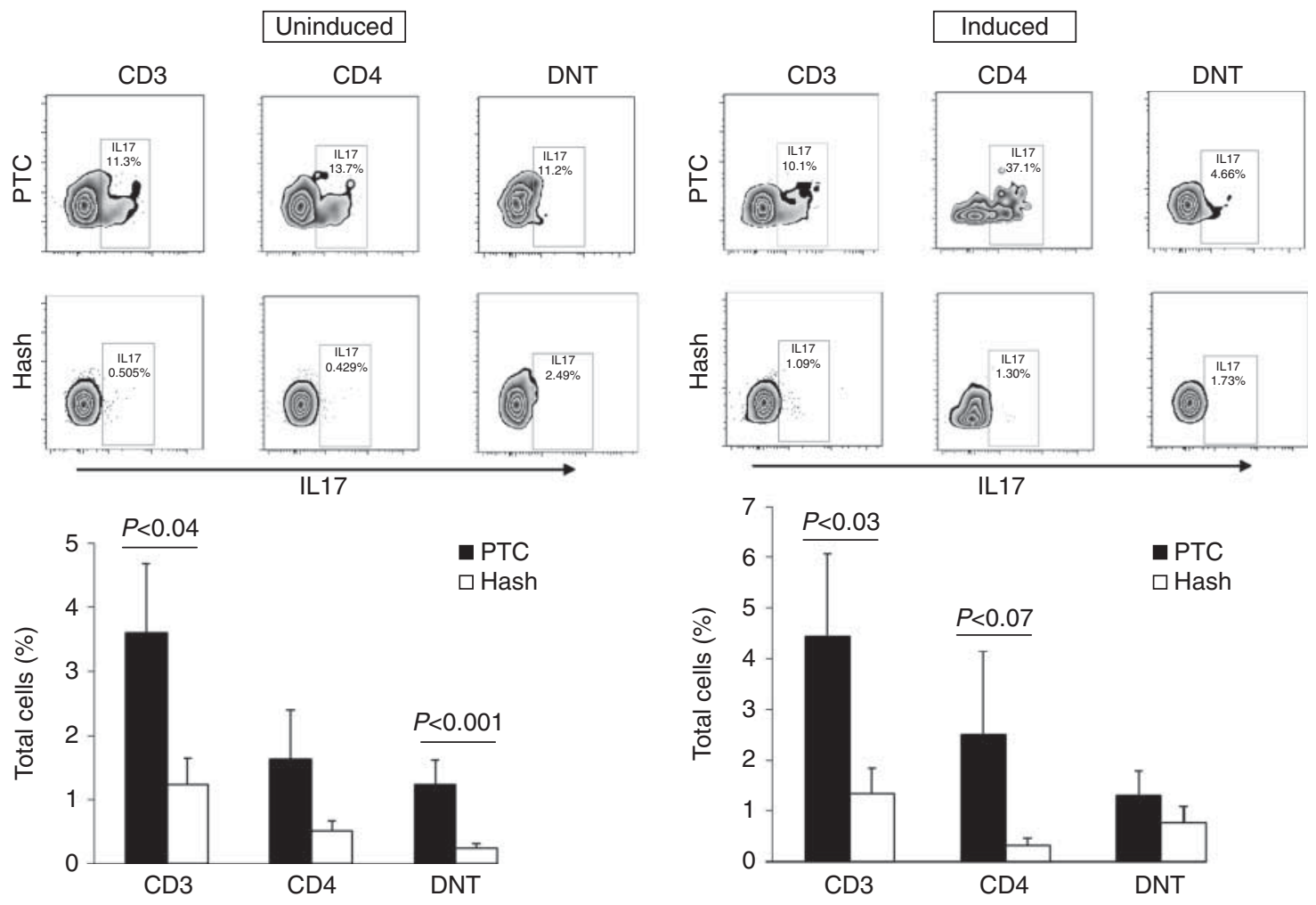

\section{Figure 6}

IL17 production by T cell type. IL17 production from the lymphocytes in patients with papillary thyroid cancer (PTC) and hypothyroid Hashimoto thyroiditis (Hash) is shown. (Left panels) Uninduced (untreated) lymphocyte FACS contour plots of representative patients (top) and bar graphs of statistical analysis of all T cells (bottom) by T cell type. (Right panels) Induced

not express CD4 or CD8 cell surface molecules and show a characteristic cytokine profile. Zhang and colleagues were the first, to our knowledge, to identify and characterize the immunoregulatory function of DN T cells. They demonstrated that murine DN $\mathrm{T}$ cells specifically eliminate activated anti-donor $\mathrm{CD}^{+}{ }^{+}, \mathrm{CD} 8^{+} \mathrm{T}$ cells and that adoptive transfer of DN T cells prolongs skin and heart allograft survival in transplant models (Zhang et al. 2006). Human DN T cells can strongly suppress the proliferation of $\mathrm{CD} 4^{+}$ and $\mathrm{CD} 8{ }^{+} \mathrm{T}$ cells too. In our study, $\mathrm{CD} 4^{+}$and $\mathrm{CD} 8^{+} \mathrm{T}$ cells were significantly affected by the presence of DN T cells in thyroid cancer (Fig. 8). Moreover, human DN T cells are able to downregulate cytokine production of highly activated human effector T cells (Merims et al. 2011). As observed in our study, human DN $\mathrm{T}$ cells produce interferon $\gamma$ (IFN $\gamma$ ) as an important mediator in the control of proliferating lymphocytes. In line with their ability to produce high levels of both IFN $\gamma$ and IL-7 (as shown in our study), DN T cells have also been reported to play a key regulatory role in various models of chronic

(PMA/ionomycin treated) lymphocyte FACS contour plots of representative patients (top) and bar graphs of statistical analysis of all T cells (bottom) by $\mathrm{T}$ cell type. IL17 was not detected in $\mathrm{CD}^{+}$cells. Black bars represent results for specimens from papillary thyroid cancer (PTC) patients. White bars represent results for specimens from hypothyroid Hashimotos' patients (Hash).

infections. DN $\mathrm{T}$ cells are the major responding $\mathrm{T}$ cell subset in the lungs of mice infected with live strain vaccine (LSV) of the intracellular bacterium Francisella tularensis. IL17-producing DN T cells do not eradicate the infection, but allow a chronic state of infection to progress. DN T-IL17-deficient mice die at day $8-10$ post LSV acute infection (Cowley et al. 2010). This indicates that IL17producing DN $\mathrm{T}$ cells allow survival by regulating the acute infection to transition into a chronic state.

In our study, we observed similar diminished singlepositive (CD4 and CD8) T cell responses in thyroid cancer. DN T cells were significantly increased while CD4 and CD8 $\mathrm{T}$ cells were significantly decreased in thyroid cancer, as opposed to what we observed in thyroid autoimmune disease (Figs 3 and 8). Although FOXP3 ${ }^{+}$Tregs were also present, DN T cells were the dominant cell type associated with thyroid cancer. Furthermore, upon stimulation/ induction, the DN T cells associated with thyroid cancer remained unchanged while the few $(<5 \%)$ DN T cells associated with thyroid autoimmune disease increased in

Published by Bioscientifica Ltd. 
A CD25

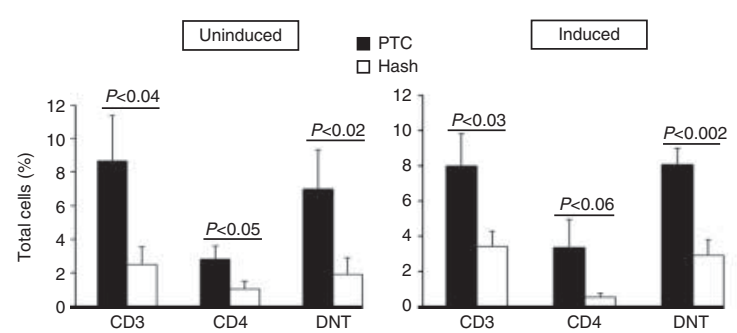

B CD14 and CD19

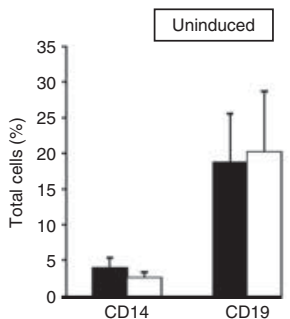

C $\quad$ CD45

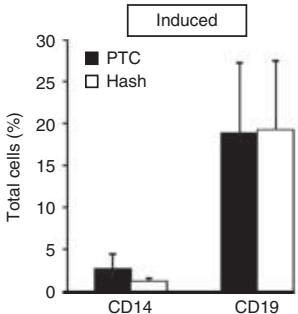

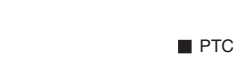

PTC
$\square$ Hash

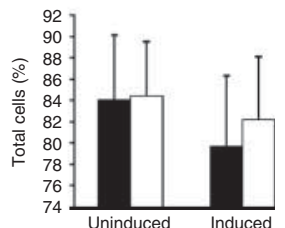

Figure 7

CD25, CD14, CD19, and CD45 in all lymphocytes. Flow cytometry of lymphocyte specimens from patients with papillary thyroid cancer (PTC) and hypothyroid Hashimoto thyroiditis (Hash) for specific immune markers. (A) Bar graphs of statistical analysis of lymphocyte specimens for the presence of CD25 (uninduced-untreated, left and induced-PMA/lonomycin treated, right) by T cell type. (B) Bar graphs of statistical analysis of lymphocyte specimens for the presence of CD14 and CD19 (uninduced-untreated, left and induced-PMA/lonomycin treated, right). (C) Bar graphs of statistical analysis of lymphocyte specimens for the presence of CD45 (uninduced-untreated and induced-PMA/lonomycin treated). Black bars represent results for specimens from papillary thyroid cancer (PTC) patients. White bars represent results for specimens from hypothyroid Hashimotos' patients (Hash).

A DNT/CD8

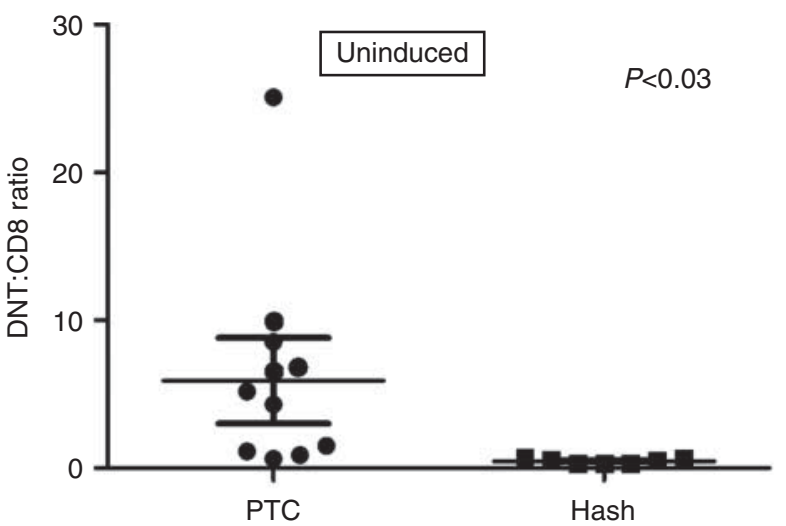

B DNT/CD4

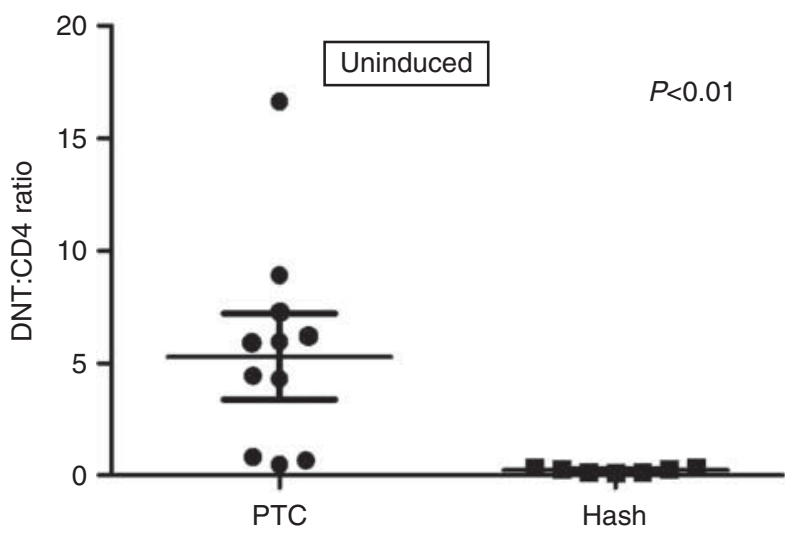

Figure 8

DNT/CD8 and DNT/CD4 T cell ratios in individual patients. The proportion of DN T cells as a function of $\mathrm{CD}^{+}{ }^{+}(\mathrm{A})$ and $\mathrm{CD} 4^{+}$(B) T cells in intra-thyroidal lymphocytes of patients with papillary thyroid cancer (PTC, circles) and hypothyroid Hashimoto's (Hash, squares) is shown. http://erc.endocrinology-journals.org DOI: 10.1530/ERC-13-0436
(C) 2014 Society for Endocrinology Printed in Great Britain 
clearly has no negative effect on their survival (Mitsiades et al. 1999). Moreover, FAS has been reported to be actually overexpressed in papillary thyroid carcinomas compared with paired normal thyroid tissues (Arscott et al. 1999). One study clearly showed that thyroid cancer cells can divert FAS signaling from apoptosis to proliferation and may actually exploit $F A S$ expression to their advantage (Mitsiades et al. 2006a,b). Another study found a germline singlenucleotide polymorphism in the FAS gene in thyroid cancer patients that might explain its increased expression (Basolo et al. 2004). Hence, aberrant FAS expression may provide the thyroid cancer hosting signal for DN T cell recruitment/ development as in lpr/gld mice and ALPS in humans.

In conclusion, our study shows for the first time that DN T cells appear to downregulate proliferation and cytokine production of activated effector $\mathrm{T}$ cells coexisting in the tumor microenvironment. In contrast, in thyroid autoimmunity, DN T cells were barely present and only increased at the expense of inactivated, single-positive $\mathrm{T}$ cells upon induction in vitro. Together, these findings indicate that thyroid-cancer-associated DN T cells might regulate proliferation and effector function of $\mathrm{T}$ cells and thereby contribute to tumor tolerance and active avoidance of tumor immunity.

\section{Declaration of interest}

The authors declare that there is no conflict of interest that could be perceived as prejudicing the impartiality of the research reported.

\section{Funding}

This work was funded in part by NIH-grants and by VA grants (J C Jaume).

\section{Acknowledgements}

The authors thank Dr Hebert Chen for sharing surgical specimens for their study. This work was presented in part at the American Association of Cancer Research Annual Meeting in Washington, DC, 2013 as a Late Breaking Abstract.

\section{References}

Abbas AK, Benoist C, Bluestone JA, Campbell DJ, Ghosh S, Hori S, Jiang S, Kuchroo VK, Mathis D, Roncarolo MG et al. 2013 Regulatory T cells: recommendations to simplify the nomenclature. Nature Immunology $\mathbf{1 4}$ 307-308. (doi:10.1038/ni.2554)

Arscott PL, Stokes T, Myc A, Giordano TJ, Thompson NW \& Baker JR Jr 1999 Fas (CD95) expression is up-regulated on papillary thyroid carcinoma. Journal of Clinical Endocrinology and Metabolism 84 4246-4252. (doi:10.1210/jcem.84.11.6139)

Baecher-Allan C \& Anderson DE 2006 Regulatory cells and human cancer. Seminars in Cancer Biology 16 98-105. (doi:10.1016/j.semcancer. 2005.11.003)
Balkwill F, Charles KA \& Mantovani A 2005 Smoldering and polarized inflammation in the initiation and promotion of malignant disease. Cancer Cell 7 211-217. (doi:10.1016/j.ccr.2005.02.013)

Basolo F, Giannini R, Faviana P, Fontanini G, Patricelli-Malizia A, Ugolini C, Elisei R, Miccoli P \& Toniolo A 2004 Thyroid papillary carcinoma: preliminary evidence for a germ-line single nucleotide polymorphism in the Fas gene. Journal of Endocrinology 182 479-484. (doi:10.1677/ joe.0.1820479)

Bennett CL, Christie J, Ramsdell F, Brunkow ME, Ferguson PJ, Whitesell L, Kelly TE, Saulsbury FT, Chance PF \& Ochs HD 2001 The immune dysregulation, polyendocrinopathy, enteropathy, X-linked syndrome (IPEX) is caused by mutations of FOXP3. Nature Genetics 27 20-21. (doi:10.1038/83713)

Cerutti E, Campagnoli MF, Ferretti M, Garelli E, Crescenzio N, Rosolen A, Chiocchetti A, Lenardo MJ, Ramenghi U \& Dianzani U 2007 Co-inherited mutations of Fas and caspase-10 in development of the autoimmune lymphoproliferative syndrome. BMC Immunology $\mathbf{8} 28$. (doi:10.1186/1471-2172-8-28)

Chang CC, Ciubotariu R, Manavalan JS, Yuan J, Colovai AI, Piazza F, Lederman S, Colonna M, Cortesini R, Dalla-Favera R et al. 2002 Tolerization of dendritic cells by $\mathrm{T}_{\mathrm{S}}$ cells: the crucial role of inhibitory receptors ILT3 and ILT4. Nature Immunology 3 237-243. (doi:10.1038/ ni760)

Chen H, Schneider D, Mazeh H, Jaume JC \& Lubner S 2013 Endocrine cancer. In Abeloff's Clinical Oncology, 5th edn. pp. 1112-1142. Eds MD Abeloff, JO Armitage, JE Niederhuber, MB Kastan \& WG McKenna. Philadelphia: Churchill Livingstone Elsevier.

Cowley SC, Meierovics AI, Frelinger JA, Iwakura Y \& Elkins KL 2010 Lung $\mathrm{CD}^{-}{ }^{-} \mathrm{CD}{ }^{-}$double negative T cells are prominent producers of IL-17A and IFN- $\gamma$ during primary respiratory murine infection with Francisella tularensis live vaccine strain. Journal of Immunology 184 5791-5801. (doi:10.4049/jimmunol.1000362)

DiSanto JP, Klein JS \& Flomenberg N 1989 Phosphorylation and downregulation of CD4 and CD8 in human CTLs and mouse L cells. Immunogenetics 30 494-501. (doi:10.1007/BF02421181)

Faria AM \& Weiner HL 2006 Oral tolerance and TGF- $\beta$-producing cells. Inflammation \& Allergy Drug Targets 5 179-190. (doi:10.2174/ 187152806778256034)

Fisher GH, Rosenberg FH, Straus SE, Dale JK, Middleton LA, Lin AY, Strober W, Lenardo MJ \& Puck JM 1995 Dominant interfering Fas gene mutations impair apoptosis in a human autoimmune lymphoproliferative syndrome. Cell 81 935-946. (doi:10.1016/ 0092-8674(95)90013-6)

Fleisher TA 2008 The autoimmune lymphoproliferative syndrome: an experiment of nature involving lymphocyte apoptosis. Immunologic Research 40 87-92. (doi:10.1007/s12026-007-8001-1)

Gogas H, Ioannovich J, Dafni U, Stavropoulou-Giokas C, Frangia K, Tsoutsos D, Panagiotou P, Polyzos A, Papadopoulos O, Stratigos A et al. 2006 Prognostic significance of autoimmunity during treatment of melanoma with interferon. New England Journal of Medicine 354 709-718. (doi:10.1056/NEJMoa053007)

Groux H, O'Garra A, Bigler M, Rouleau M, Antonenko S, de Vries JE \& Roncarolo MG 1997 A CD4 ${ }^{+}$T-cell subset inhibits antigen-specific T-cell responses and prevents colitis. Nature 389 737-742. (doi:10.1038/39614)

Jaume JC 2011 Endocrine autoimmunity. In Greenspans' Basic and Clinical Endocrinology, 9th edn, pp 27-46. Eds GC Gardner \& DM Shoback. New York: McGraw-Hill Medical.

Jin YJ, Zhang X, Boursiquot JG \& Burakoff SJ 2004 CD4 phosphorylation partially reverses Nef down-regulation of CD4. Journal of Immunology 173 5495-5500. (doi:10.4049/jimmunol.173.9.5495)

Korman A, Yellin M \& Keler T 2005 Tumor immunotherapy: preclinical and clinical activity of anti-CTLA4 antibodies. Current Opinion in Investigational Drugs 6 582-591.

Kriegel MA, Lohmann T, Gabler C, Blank N, Kalden JR \& Lorenz HM 2004 Defective suppressor function of human $\mathrm{CD} 4{ }^{+} \mathrm{CD} 25^{+}$regulatory $\mathrm{T}$ 
cells in autoimmune polyglandular syndrome type II. Journal of Experimental Medicine 199 1285-1291. (doi:10.1084/jem.20032158)

Marlies A, Udo G, Juergen B, Bernd S, Herrmann M \& Haas JP 2007 The expanded double negative $T$ cell populations of a patient with ALPS are not clonally related to $\mathrm{CD}^{+}$or to $\mathrm{CD} 8^{+} \mathrm{T}$ cells. Autoimmunity $\mathbf{4 0}$ 299-301. (doi:10.1080/08916930701356473)

Mellman I, Coukos G \& Dranoff G 2011 Cancer immunotherapy comes of age. Nature 480 480-489. (doi:10.1038/nature10673)

Merims S, Li X, Joe B, Dokouhaki P, Han M, Childs RW, Wang ZY, Gupta V, Minden MD \& Zhang L 2011 Anti-leukemia effect of ex vivo expanded DNT cells from AML patients: a potential novel autologous T-cell adoptive immunotherapy. Leukemia 25 1415-1422. (doi:10.1038/leu.2011.99)

Mirocha S, Elagin RB, Salamat S \& Jaume JC 2009 T regulatory cells distinguish two types of primary hypophysitis. Clinical Experimental Immunology 155 403-411. (doi:10.1111/j.1365-2249.2008.03828.x)

Mitsiades N, Poulaki V, Mastorakos G, Tseleni-Balafouta ST, Kotoula V, Koutras D \& Tsokos M 1999 Fas ligand expression in thyroid carcinomas: a potential mechanism of immune evasion. Journal of Clinical Endocrinology and Metabolism 84 2924-2932. (doi:10.1210/jcem.84.8.5917)

Mitsiades N, Poulaki V, Tseleni-Balafouta S, Koutras DA \& Stamenkovic I 2000 Thyroid carcinoma cells are resistant to FAS-mediated apoptosis but sensitive to tumor necrosis factor-related apoptosis-inducing ligand. Cancer Research 60 4122-4129.

Mitsiades CS, Poulaki V, Fanourakis G, Sozopoulos E, McMillin D, Wen Z, Voutsinas G, Tseleni-Balafouta S \& Mitsiades N 2006a Fas signaling in thyroid carcinomas is diverted from apoptosis to proliferation. Clinical Cancer Research 12 3705-3712. (doi:10.1158/1078-0432.CCR-05-2493)

Mitsiades N, Poulaki V, Tseleni-Balafouta S, Koutras DA \& Stamenkovic I $2006 b$ Thyroid carcinoma cells are resistant to FAS-mediated apoptosis but sensitive to tumor necrosis factor-related apoptosis-inducing ligand. Cancer Research 60 4122-4129.

Mohamood AS, Bargatze D, Xiao Z, Jie C, Yagita H, Ruben D, Watson J, Chakravarti S, Schneck JP \& Hamad AR 2008 Fas-mediated apoptosis regulates the composition of peripheral $\alpha \beta \mathrm{T}$ cell repertoire by constitutively purging out double negative T cells. PLOS ONE 3 e3465. (doi:10.1371/journal.pone.0003465)

Paparodis R, Imam S, Todorova-Koteva K, Staii A \& Jaume JC 2014 Hashimoto thyroiditis pathology and risk for thyroid cancer. Thyroid (published online ahead of print). (doi:10.1089/thy.2013.0588)

Poppema S, Maggio E \& van den Berg A 2004 Development of lymphoma in autoimmune lymphoproliferative syndrome (ALPS) and its relationship to Fas gene mutations. Leukemia \& Lymphoma 45 423-431. (doi:10.1080/10428190310001593166)

Prehn RT \& Main JM 1957 Immunity to methylcholanthrene-induced sarcomas. Journal of the National Cancer Institute 18 769-778.
Romero P, Dunbar PR, Valmori D, Pittet M, Ogg GS, Rimoldi D, Chen JL, Liénard D, Cerottini JC \& Cerundolo V 1998 Ex vivo staining of metastatic lymph nodes by class I major histocompatibility complex tetramers reveals high numbers of antigen-experienced tumor-specific cytolytic T lymphocytes. Journal of Experimental Medicine $\mathbf{1 8 8}$ 1641-1650. (doi:10.1084/jem.188.9.1641)

Sakaguchi S 2000 Regulatory T cells: key controllers of immunologic self-tolerance. Cell 101 455-458. (doi:10.1016/S0092-8674(00) 80856-9)

Schreiber RD, Old LJ \& Smyth MJ 2011 Cancer immunoediting: integrating immunity's roles in cancer suppression and promotion. Science $\mathbf{3 3 1}$ 1565-1570. (doi:10.1126/science.1203486)

Shirai T, Abe M, Yagita H, Okumura K, Morse HC III \& Davidson WF 1990 The expanded populations of $\mathrm{CD}^{-} \mathrm{CD}^{-} \mathrm{T}$ cell receptor $\alpha / \beta+\mathrm{T}$ cells associated with the lpr and gld mutations are CD2. Journal of Immunology 144 3756-3761.

Teachey DT, Manno CS, Axsom KM, Andrews T, Choi JK, Greenbaum BH, McMann JM, Sullivan KE, Travis SF \& Grupp SA 2005 Unmasking Evans syndrome: T-cell phenotype and apoptotic response reveal autoimmune lymphoproliferative syndrome (ALPS). Blood 105 2443-2448. (doi:10.1182/blood-2004-09-3542)

Turk MJ, Guevara-Patino JA, Rizzuto GA, Engelhorn ME \& Houghton AN 2004 Concomitant tumor immunity to a poorly immunogenic melanoma is prevented by regulatory T cells. Journal of Experimental Medicine 200 771-782. (doi:10.1084/jem.20041130)

Valmori D, Scheibenbogen C, Dutoit V, Nagorsen D, Asemissen AM, Rubio-Godoy V, Rimoldi D, Guillaume P, Romero P, Schadendorf D et al. 2002 Circulating tumor-reactive $\mathrm{CD}^{+} \mathrm{T}$ cells in melanoma

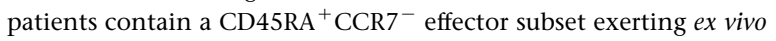
tumor-specific cytolytic activity. Cancer Research 62 1743-1750.

Watanabe D, Suda T, Hashimoto H \& Nagata S 1995 Constitutive activation of the Fas ligand gene in mouse lymphoproliferative disorders. EMBO Journal 14 12-18.

Wherry EJ 2011 T cell exhaustion. Nature Immunology 12 492-499. (doi:10.1038/ni.2035)

Wildin RS, Ramsdell F, Peake J, Faravelli F, Casanova JL, Buist N, Levy-Lahad E, Mazzella M, Goulet O \& Perroni L 2001 X-linked neonatal diabetes mellitus, enteropathy and endocrinopathy syndrome is the human equivalent of mouse scurfy. Nature Genetics $\mathbf{2 7}$ 18-20. (doi:10.1038/83707)

Zhang ZX, Yang L, Young KJ, DuTemple B \& Zhang L 2006 Identification of a previously unknown antigen-specific regulatory $\mathrm{T}$ cell and its mechanism of suppression. Nature Medicine 6 782-789. (doi:10.1038/77513)

Received in final form 6 February 2014

Accepted 24 February 2014

Made available online as an Accepted Preprint

28 February 2014 http://erc.endocrinology-journals.org

DOI: 10.1530/ERC-13-0436
(C) 2014 Society for Endocrinology Printed in Great Britain
Published by Bioscientifica Ltd. 